small number of potentially curable patients could be detected with some certainty at this stage many others might be spared fruitless further investigation. The standard intravenous pyelogram (I.V.P.) is not adequate to this end, failing to select about half of those with renovascular hypertension. ${ }^{511}$ It gives excellent information about important correctable lesions like unilateral hydronephrosis, pyelonephritis, or tuberculosis, but these play only a small part in renal hypertension. In cases of unilateral renal ischaemia major structural changes in kidney or ureter may be evident. Attempts to improve the diagnostic value of the I.V.P. have been based on studies of asymmetric patterns in the excretion of contrast medium deriving from the selective sodium and water reabsorption in the ischaemic kidney. ${ }^{12}$

Films taken at minute intervals after the injection of contrast medium show up any delay in the appearance of contrast, and this technique has been of help in some hands. ${ }^{13}$ However, when differences between the two sides are small, perhaps a minute or less, interpretation can be difficult. ${ }^{14}$ Increased density of contrast medium due to marked reabsorption of water in the affected kidney can also cause confusion. To accentuate the asymmetry of contrast density $\mathrm{K}$. Amplatz ${ }^{15}$ proposed establishing an osmotic diuresis in the course of the I.V.P. by infusion of urea, thus allowing comparison between the rapid wash-out of contrast from the normal kidney with contrast retention in the ischaemic, oliguric kidney. The early reports of this technique of "radiological divided renal-function studies" suggested a much-improved detection rate of renovascular hypertension, with no false-negative results in the sense of failures to select patients improved by surgery, though "pseudopositive" results to the test were reported.16 17 . H. Schreiber and colleagues ${ }^{18}$ have recently laid down a range for the normal and shown that the test does not contribute

1 Lawrence, J. R., Doig, A., Knight, I. C. S., MacLaren, I. F., and Donald, K. W., Lancet, 1964, 1, 62.

2 Holley, K. E., Hunt, J. C., Brown, A. L., Kincaid, O. W., and Sheps, S. G., Amer. F. Med., 1964, 37, 14 .

3 Smith, H. W., f. Urol. (Baltimore), 1956, 76, 685.

- Chamberlain, M. J., and Gleeson, J. A., Lancet, 1965, 1, 619.

- DeBakey, M. E., Morris, G. C., Morgen, R. O., Crawford, E. S., and Cooley, D. A., Amer. F. Surg., 1964, 107, 84 .

- Poutasse, E. F., ibid., 1964, $107,97$.

- Maxwell, M. H., and Prozan, G. B., Progr. cardiovasc. Dis., 1962, 5, 81.

- Sutton, D., Brunton, F. J., and Starer, F., Clin. Radiol., 1961, 12, 80.

- Brown, J. J., Owen, K., Peart, W. S., Robertson, J. I. S., and Sutton, D., Brit. med. F., 1960, 2, 327.

10 Owen, K., Brit. f. Urol., 1964, 36, 7.

11 Spencer, F. C., Stamey, T. A., Bahnson, H. T., and Cohen, A., Ann. Surg., 1961, 154, 674.

12 Mueller, C. B., Surtshin, A., Carlin, M. R., and White, H. L., Amer. F. Physioi., 1951, 165, 411 .,

1s Maxwell, M. H., Gonick, H. C., Wiita, R., and Kaufman, J. J., New Engl. Э. Med., 1964, 270, 213.

14 Fenton, S. S. A., Lyttle, J. A., and Pantridge, J. F., Lancet, 1966, 2, 117 .

18 Amplatz, K., Radiology, 1962, 79, 807.

16 Stejskal, R. E., Staub, E. V., Loken, M. K., and Amplatz, K., Amer. 7. Roentgenol., 1964, 92, 1397.

17 Schreiber, M. H., Sarles, H. E., Herring, M. E., and Remmers, A. R., New Engl. F. Med., 1964, 270, 1223.

18 Schreiber, M. H., Remmers, A. R., Sarles, H. E., and Smith, G. H. Amer. Э. Roentgenol., 1966, 98, 88.

10 Witten, D. M., Hunt, J. C., Sheps, S. G., Greene, L. F., and Utz, D. C., ibid., 1966, 98, 114.

20 Doig, A., Lawrence, J. R., Philp, T., Tothill, P., and Donald, K. W., Brit. med. ₹., 1963, 1, 500 .

21 Farmelant, M. H., Lipetz, C. A., Bikerman, V., and Burrows, B. A., Amer. F. Surg., 1964, 107, 50.

22 Andrews, D., Parsons, V., and Roebuck, E. J., Brit. F. Radiol., 1965, $38,527$.

23 Luke, R. G., Briggs, J. D., Kennedy, A. C., and Stirling, W. B., Quart. f. Med., 1966, 35, 237.

s Kennedy, A. C., Luke, R. G. Briggs, J. D., and Stirling, W. B., Lancet, 1965, 2, 963. to the diagnosis of bilateral renovascular disease. The whole place of "wash-out" pyelograms in this field has now been questioned by D. M. Witten and his colleagues, ${ }^{19}$ who used mannitol infusion during the I.V.P. in preference to urea, to avoid the latter's potential hazards.

If the success rate of the intravenous pyelogram in the diagnosis of renovascular hypertension can be increased only from $50 \%$ to between $60 \%$ and $70 \%$ by these various refinements it is reasonable to look in other directions for a complementary outpatient screening test of individual renal function. After an uncertain start the hippuran radioisotope renogram has for some time been used with success. ${ }^{20-22}$ The careful work of R. G. Luke and his colleagues ${ }^{23}$ has now confirmed it as a simple, safe, and rapid investigation in the search for renovascular hypertension. Performed with care and used in conjunction with an initial I.V.P., the incidence of false-negative and false-positive assessments can be kept below $5 \% .24$ This is a fairly good rate of detection, and one that materially helps to prevent fruitless further investigation.

On present-day evidence the best way of selecting those hypertensive patients who may benefit from further inpatient investigation into a renal cause of their disease is to perform an intravenous pyelogram, supplemented by radiographs during the first five minutes of the examination, and to follow this with a radioisotope renogram.

\section{Mediastinal Emphysema}

Mediastinal emphysema has the distinction of being one of the very few conditions which enable the heart beats to be heard from the foot of the bed. With the stethoscope the "crunching" sound described by L. Hamman" is usually heard best down the left border of the heart; it varies in intensity and may be absent. If the sign is associated with subcutaneous emphysema of the neck or chest the diagnosis of mediastinal emphysema is virtually certain. The radiological appearances are characteristic, showing a small air space running parallel to the left, and sometimes the right, border of the heart. There may be an associated pneumothorax.

Air may enter the mediastinum by any of several routes. The commonest, as in so-called benign mediastinal emphysema, seems to be through the pulmonary alveoli, when a small rupture causes a pressure gradient between the alveoli and adjacent connective tissue. ${ }^{2}$ The mechanism of such a gradient is obscure, but it seems at times to be precipitated by pulmonary emphysema, asthma, pneumonia, or childbirth. Once the air has entered the tissue it takes the line of least resistance and passes along the perivascular sheaths to the mediastinum and thence to the subcutaneous tissue. Ordinarily it does not extend far beyond the neck and in the benign form subsides within a few days. But occasionally the air spreads beyond the neck to the hand, arms, trunk, and even the legs, in which case there is a danger of suffocation. The other possible complication is the so-called " malignant" form of mediastinal emphysema, in which the pressure of air

\footnotetext{
1 Hamman, L., Trans. Ass. Amer. Phycns, 1937, 52, 311.

'Macklin, M. T., and Macklin, C. C., Medicine (Baltimore), 1944, 23, 281.

3 Gray, J. M., and Hanson, G. C., Thorax, 1966, 21, 325.
} 
in the mediastinum becomes excessive and embarrasses the action of the heart. This can be fatal, especially if tension pneumothorax coexists.

Other modes of entry of air into the mediastinum include rupture of the trachea, bronchus, or oesophagus from any cause and penetrating wounds of the lung and mediastinal pleura. These are clearly formidable conditions and must always be considered in patients who develop mediastinal emphysema.

There are thus two different clinical problems. In the commoner, benign, form a patient may present with no more than a vague precordial ache, ${ }^{3}$ possibly with Hamman's sign and some subcutaneous emphysema of the neck. A careful watch needs to be kept in case complications develop, but usually the prognosis is excellent. If the emphysema spreads or the patient becomes breathless or shows signs of collapse, immediate removal to hospital, preferably to a thoracic surgical unit, is essential. A radiograph of the chest will confirm the mediastinal emphysema; it will also show a pneumothorax and the extent of any preceding trauma. If oesophageal rupture is suspected, surgical treatment is imperative as soon as possible. The diagnosis may not be easy, but a rapidly developing state of shock, and upper abdominal rigidity in cases of perforation of the lower oesophagus, are suggestive and call for $x$-ray examination by Gastrografin swallow. Only slightly less urgent is oversuture of a rupture of the trachea or bronchus. Malignant mediastinal emphysema may be relieved by needling parallel to the deep surface of the sternum, but cervical mediastinotomy or even a sternal split may be necessary. Tension pneumothorax is best treated with a wide-bore intercostal tube. Extensive subcutaneous emphysema may be relieved by "milking" the air through small incisions in the skin.

\section{Frozen Poultry and Staphylococcal Food-poisoning}

Two recent reports from Australia ${ }^{1}$ and the U.S.A. ${ }^{2}$ have suggested that frozen poultry meat may be a common source of staphylococcal enterotoxin food-poisoning. No figures for the incidence of staphylococcal food-poisoning, either in relation to other causal agents or in relation to the various foods responsible for outbreaks, were given by Anderson. Nevertheless, C. Genigeorgis and W. W. Sadler ${ }^{2}$ quote G. M. Dack ${ }^{3}$ as saying that in the years 1956 to 1961 poultry meat was the third most frequent food (after meat and bakery products) implicated in outbreaks of staphylococcal enterotoxin food-poisoning.

Records of food-poisoning incidents in the United Kingdom are compiled by the Public Health Laboratory Service from reports received from public health and hospital laboratories, and from notifications sent by medical officers of health to the Ministry of Health. A report is published annually in the Bulletin of the Ministry of Health and Public Health Laboratory Service. A study of these statistics up to 1966 does not suggest that staphylococcal food-poisoning and poultry meat have often been associated in the past. Thus not more than one or two outbreaks have been recorded in any one year. The number of incidents of staphylococcal food-poisoning reported every year has varied between 74 and 143 during the last decade, while the foods usually concerned were cold meat, such as ham and tongue, and sweet dishes, such as cakes and trifles.

One explanation for these apparent differences may be that both the methods of manufacture for poultry products and the national feeding habits in Australia and the U.S.A. are different from those in Britain. Thus the manufacture and distribution of cooked and frozen poultry rolls made up of compressed meat in plastic wrapping is commoner in the U.S.A. and Australia-though these have recently been imported and produced in Britain, and this may increase the likelihood of staphylococcal food-poisoning from poultry meat. Any food handled after cooking and before freezing may be contaminated with staphylococci from the hands of the workers and from the processing equipment. Whether the food remains safe will depend on the time between cooking, handling, and freezing and on the actions of the caterer or householder responsible for the preparation of food for the table. To produce enough toxin to cause food-poisoning staphylococci must grow in food, and every hour that the latter is exposed to room temperature increases the risk considerably. Moreover, washing the hands before handling food is no safeguard against the removal of staphylococci, which are well known to stick closely to the hands within the skin and in crevices and to defy all efforts at removal. ${ }^{4}$

Another question that has to be answered is whether the prevalence of coagulase-positive staphylococci could be due to their frequent occurrence in the birds themselves or in poultry workers, who then contaminate the environment. The broiler trade is troubled by staphylococcal sepsis in poultry, but little is known of the epidemiology of this disease or of its relation to the staphylococci carried by the workers in the intensive poultry farms and factories.

The multiplication of staphylococci on chicken meat before cooking could give rise to enterotoxin in situations inside the bird where heat penetration is poor, so that the toxin or perhaps even the organism itself would not be destroyed during cooking. But despite the heat resistance of enterotoxin, and despite the prevalence of Staphylococcus aureus in the slaughter-houses, ${ }^{5}$ there are no reports of staphylococcal food-poisoning from meat contaminated when raw and subsequently eaten shortly after cooking. The survival of coagulase-positive staphylococci in lightly cooked meat or poultry could result in multiplication during long, slow cooling periods, yet it is the survival of salmonellae-and more particularly Clostridium welchii-which has given rise to many reported outbreaks of food-poisoning. The spores of $\mathrm{Cl}$. welchii readily survive cooking temperatures, and germinate into actively growing bacilli in slowly cooling masses of meat and poultry, particularly those of large bulk. Thus at present codes of practice for caterers and housewives are under consideration. What is also badly needed are codes of practice for means and materials to clean equipment and working surfaces soiled by raw food materials, which bring food-poisoning organisms into the kitchen.

\footnotetext{
Anderson, K., Med. 7. Aust., 1966, 2, 1223.

2 Genigeorgis, C., and Sadler, W. W., Poult. Sci., 1966, 45, 973.

3 Dack, G. M., in International Symposium on Food Protection, Chemical and Biological Hazards in Foods, ed. by J. C. Ayres et al., 1962, p. 320. Iowa

- Brodie, J., Scot. med. f., 1965, 10, 115.

s Ludlam G. B., Mth. Bult. Minist. Hlth Lab. Serv., 1952, 11, 138
} 